\title{
MARRIAGE SYSTEM OF THE BODOS AND ASSOCIATED RITES AND RITUALS
}

\author{
Dr. Sekhar Brahma ${ }^{1}$, Registrar, Bodoland University, Dr. Oinam Ranjit Singh ${ }^{2}$ (Corresponding \\ Author), Associate Professor, Department of History, Bodoland University, Nijwm Gwra Brahma ${ }^{3}$ Ph.D. \\ Scholar, Department of History, Bodoland University
}

\begin{abstract}
Marriage is a very important institution in human society which permit man and women in family life i.e. husband and wife. The Bodo has well established institutions of the marriage. No doubt, they are monogamous not polygamous. Polendery form of marriage is absolutely absent in Bodo society. Various rites and rituals have been associated in the marriage ceremonies of the Bodos which have been practiced since the time immemorial. In this paper a modest attempt is made to highlight and study the marriage system of the Bodos and associated rites and the rituals.
\end{abstract}

Key Words: Swngnai Haba, Gwrjiya Lakhinai Haba, Kharsonnai Haba, Bwnanwi Lainai Haba, Dwnkharnai Haba, Dongkha habnai Haba

\section{INTRODUCTION}

North-East India has been diverse multi ethnic tribal groups with their unique tradition and culture which are very rich and varied and socially mingling into the mainstream of the India. It is the only region to see the unity and diversity of India where natural beauty, calm atmosphere, crowd and splendid strife of different tribes has originated. Though their culture may be different with each other but originally the charms and beauties are reflecting deeply through their dances, music, dresses of hills and plains areas in the heart of the tribal people of North-East India. Both orient and Western researchers contributed for the development of North-Eastern region in regard to focused with the other civilized cultures. Therefore, tribal cultures also no marginalized from the other developed cultures hold close to them and seeks unity in diversity.

Assam is a symbolized of multi-ethnic groups with multi cultural and historical background. Of various ethnic tribal groups, the Bodo tribe is one of the prominent and the oldest inhabitants of North-east particularly in Assam. Racially Bodos belonged to the Mongoloid stock of the indo-Mongoloid or Indo-Tibetans.The Bodo speakers of the Tibeto-Burman branch of the Tibeto-Chinese family who belong to the Mongoloid group and have drawn their tribal elements from the Boros, the Dimasas, the Garos, the Rabhas, the Koches, the Chutiyas, the Tripuris, the Hajongs, the Lalungs etc.

Dr. Suniti Kumar Chatterjee, "The Bodos spread over all Brahmaputra valley and North Bengal forming a solid block in Eastern India and they formed one of the main bases of the present day population of this tract" (S.K. Chatterjee, 2007: 45-46). Majority of the Bodos are found on the Northern Bank of the Brahmaputra valley but now they spread all over Assam, North Bengal and in some parts of Arunachal Pradesh, Nagaland, etc.

\section{OBJECTIVE OF THE STUDY}

The objective of the study is to highlight and study the institution of the marriage and different rites and rituals that associated in the traditional marriage ceremony of the Bodo. Many rites and rituals have been used in the marriage ceremony but they are not collected and written down fully. With the sole objective of understanding the ritual ceremony of the marriage and system of the marriage, this paper has been developed.

\section{METHODOLOGY}

The methodology adopted in this paper is inter-disciplinary approach which included consulting number of written sources as well as interview method. The people who have knowledge on the traditional 
marriage of the Bodo and various rites and rituals that associated in the marriage have been consulted and information also has been gathered from published work and journals.

\section{RESULT AND DISCUSSION}

Marriage is one of the most important ceremonies in the life circle of every community of the world. In Bodo society monogamy is the chief form of marriage but in some exceptional cases polygamy is also found. Polyandry is strictly prohibited and absent in Bodo society. Bodos have different type of marriage. These are (a) Swngnai Haba (Arranged Marriage), (b) Kharsonnai Haba (Girl flee away), (c). Gwrjiya Lakhinai Haba (Groom staying with Brides family in their house), (d) Dwnkharnai Haba (Elopement) and (e) Dongkha Habnai Haba means widow re-marriage (Brahma, 2006: 21)

\section{A. Swngnai Haba (Arranged Marriage)}

Swngnai Haba is the most important and regular form of marriage among Bodos. This marriage system is made mutual agreement with both the parties; fixed a suitable day and date and held with merry making along with the traditional customs. In earlier days this type of marriage is mainly solemnized at the house of bridegroom and till today it is existed. Though some parents of the Bodos solemnized at the bride's house but it is very rare.

\section{B. Gwrjiya Lakhinai Haba(Obtaining girl by service)}

Gwrjiya Lakhinai Haba of marriage is solemnized at the house of bride only who had no male child. Before marriage the groom has to give his service at the house of bride. Even after the marriage he is required to rendered service to the family of his wife by staying at house of his wife original family till his death. This marriage is practiced to those who do not have son. The aim of this marriage is to make look after the family of the wife by the husband when the parents of the wife become aged. So, to take care of their family they keep male person as Gwrjiya.

\section{Kharsonnai Haba (Girl flee away)}

When the girls refused parents proposal of her marriage and flee away to her lover house then it is called Karsonnai Haba (Girl flee away) by the Bodos. In this marriage the bride enters to the bridegroom's house before the settlement and starts living with his family. In this situation the parents or elders of the house fixed a day and get them to marry.

\section{Bwnanwi Lainai Haba (Marriage by capture)}

When a girl is forcefully taken to the house of boy and gets married, it is called Bwnanwi Lainai Haba (Marriage by capture). Earlier it was very common in the Bodo society but now days it become very rare. This type of marriage is not socially recognized in the Bodo society.

\section{E. Dwnkharnai Haba (Elopement)}

In this marriage both boy and girl run away from their parent's house in an aloofness place and silently get married. It is not prevalent in the Bodo society but sometimes it happens. This type of marriage is not approved socially in the Bodo society.

\section{F. Dongkha habnai Haba (Widow Remarriage)}

It is a socially approved marriage in the Bodo society. In this marriage, a widow can bring the new groom to her house and can live the conjugal life with the agreement of both and the man who marries the widow must live in the bride's house for life long. There is some traditional custom in this marriage that the new groom gives a silver coin to her with this word, 'dinwiniprai ang nwngni, nwng angni' (Narzee 2006: 79) (from today you are mine, I am your's). The giving of coin is called gangkhon hwnai.

In the Dongkha Habnai Haba (widow remarriage), the man has to leave his own parents and relatives. During the time of leaving his relatives, he should worship the Anan Gosai (God) and the grant feast is organised for the villagers where the abundance of jau, (wine), oma bedor (pork), wngkham (rice) etc. are offered. Daosa jorase (a pair of chicken), jau gisi dabkha jorase (a pair of earthen pot homemade wine), dhupdhuna, goi jora-pathwi jora(pair of betel nut and betel leave) are offered to the Bwrai Bathau by reciting the following hymns:

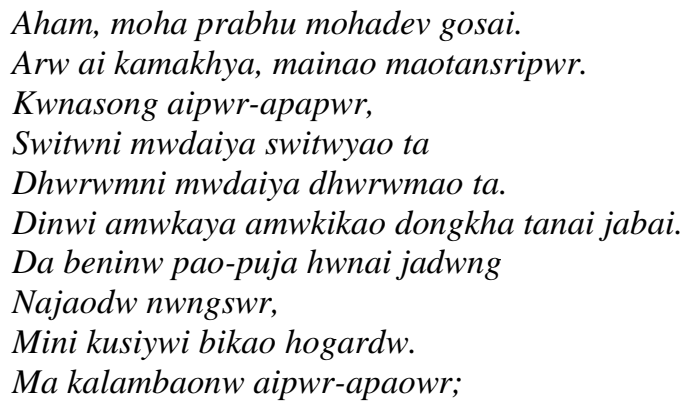




\section{Amwkani jwnwmao bikaonw lirdwng kwma}

Bikao nwngtangmwnhasw miti sigwo. (Narzee, 2006: 80)

English meaning: Aham, Prabhu Mohadev, mother Kamakya and Mainao, listen, holly deity should be in truth, and today (name of groom) is going married the widow for that Puja is offering to you, accept him happily.

The man who is undergoing Gwrjiya Lakhinai Haba should kneel down in front of the Bathau. After the finished of Mwntwr (prayer), he has to give three pieces of dried jute which is called by the Bodos as narji gwran orgarnai to the groom. The person who entered into Gwrjiya Lakhinai Haba should not have any right on the property of his parent.

Another traditional believed in this system of marriage is that the widow keeps one pot of pork or chicken, one pot of rice beer in front of the Noma No (main house) lighting a jeowary and wait along with flat ladle just like to beat. Then the man who will be Dhongkha wears rice pot on his head and should make round the widow's house for seven times and each round he tried to enter the Noma No but defended by the bride as the widow threat him to driven out. At the last round, if the man arrives in front of the door the widow asked by remembering her death husband Amwkani bipasw nama? Then the man should give the answer yes. When the answer of the yes comes from the groom, he is allowed to enter the Noma No. He is offered meat and rice bear. In this way the Dongkha habnai Haba(widow remarriage) is celebrated by the Bodos.

Marriage is a very important social institution. Besides, procreation and peaceful conjugal lives, the human beings are attached closely with the society. Thus, the marriage institution is an important social system for the welfare and discipline in the society(Brahma, 2009: 65) In Bodo, 'Marriage' means 'Haba'(Brahma, 2008: 15) ' $\mathrm{Ha}$ ' means 'Soil' and ' $\mathrm{Ba}$ ' means 'To Carry'. So, 'Haba' means "To take the soil on the back". In Bodo, marriage, two females play important part who are called 'Bwirathi'(Mwshahary, 2010: 69) In ancient times, they were called 'Barjhw'. No widow or widower is allowed to perform as Bhwirathi. A male principle called 'Barlhangpha' is also another important person in the Bodo marriage who also company by the 'Bwirathi'. He used to wear wonderful things and items around his neck. He takes a garland made of old 'papaya' fruits around his neck and used to play flute in hand. He used to lead the marriage procession and dance along with the Bwirathi. He used to dance like a wave of cool breeze by playing flute with the both hands. From the way of his act and making entertainment he is known as Barlangpha which is the combination of two words Bar + Langpa=Barlampa (Brahma, 2008: 15). Bar is called air in Bodo and Langpa means dancing like the wave.

\section{Pre Marriage:}

A negotiation between the families of bride and bridegrooms for the settlement of the marriage is called Pre-Marriage. For that purpose the parent of the bridegroom with some elder members of the village has to carry a pair of bracelets (Asanshuri Jorase), a pair of one rupee (coin), a pair of areca nuts, a pair of betel leaves and a pair of rice beer bottles to the house of the bride and explain the purpose of their visit to the parents of the bride with some proverbs as follow:

"Jerao Thuri nuyw beounw bathi garw

Jerao jwn nuyw beonw goi kitao garw” (Narzi, 2006: 63).

English translation: Where is thatch, a piece of stick dropped, where spear backside of betel nut is thrown.

After explaining the purpose of their visit the members of the bridegroom leave these things at the house of the bride. Within a week from the date of the first approach of the bridegroom party, if the parents of the bride do not return the pair of bracelets and a pair of one rupee (coin) then it is understood by the parents of the bridegroom that the parents of the bride agreed their proposal. If the parent of the bride is agreed then after some days the parents of both the families sit together along with village headman and some elder members of the family for the final settlement of marriage. Before marriage, a ceremony is observed according to their traditional custom. For this purpose the parent of the bridegroom visit the house of bride with some elder members of the village. The bridegroom party carries two bottle of rice beer, a bundle of areca nuts and betel leaves to the bride's house. This ceremony is called 'Goi Khaonai'(Devi, 2007: 97). After some weeks or months another ceremony is performed by the bridegroom's party according to their traditional custom. This ceremony is called 'Biban langnai'. For the ceremony two earthen pitchers full of rice beer, areca nuts and betel leaves are brought to the house of the bride. The signs of the sun and the moon are painted on the body of the two pitchers. The Biban (two pitchers) is carried by a person known as 'Barlangpha'(Brahma, 2008: 15). Along with Barlangpha two ladies are necessary for the marriage ceremony. They are called Bwirathi. The main duty of Bwirathi is to cut the areca nuts and betel leaves and to distribute to the people of the brides party. No widow or widower is allowed to perform the role of Barlangpha and Bwirathi. In some areas of Baksa and Udalguri district of B.T.A.D. area four girls are selected to perform the role of Bwirathi and they are called Barjw. But in Kokrajhar and Chirang district of B.T.A.D. area only two girls are selected.. The last stage of pre marriage 
ceremony is called 'Kobira Lainai'(Informant : Bena Brahma, age 60 years, Vill- Santinagar, Dotma). For this ceremony the parents of the bridegroom and the bride along with the village headman and some elder members of the village sit together at the house of the bride and fix the suitable date of the proper marriage.

\title{
II. Traditional Marriage:
}

The traditional marriage system of the Bodo is called 'Hathasuni khurnai' (Brahma, 2006: 21). On the fixed date of the proper marriage, the parents of the bridegroom with Barlangpha and two Bwirathies and other some elder members of the village and relatives has go to the residence of the bride to bring the bride for marriage which is known as Hinjao gwdan lainw Thangnai (to go for bringing the new bride). Two Bairathies are dressed up beautiful and colourful with new traditional dresses. This is called 'Dhokona Thaosi'(Dharani Kanta Narzary, age 62, Vill- Laokriguri, Kokrajhar). The Biban is carried by Barlangpha. The Biban consists of areca nuts and betel leaves, milk, etc. in abundance. The two Bairathies are required to serve areca nuts and betel leaves to the villagers of the bride. When the bride is about to be taken away from the house of her parent, the old women and her relatives console the bride with the following folk song:-

\author{
"Dagabswi aywi dagabswi \\ Oma gidira Boro khurmani, \\ Phisa hinjaoa malaini. \\ Nepal, Gongernw horakhwi \\ Harsa houanw horakhwi \\ Raijw janw Boro houanwsw hordwng”(Narzi, 2006: 74).
}

English translation: Do not weep, do not weep dear, the big pig is for kith and kins, a grown up girl is for other. You have neither been given to a Nepali or Bhutia nor to an outcast but to a Boro youth to lead a proper family life. While bridegroom's party and bride's party along with bride arrive at the house of the bridegroom, the members of the bridegroom family wash bride's feet with water at the front gate of the house. During the marriage ceremony Barlangpha and Bairathies sings and dances. After dressing up the bride and bridegroom, the proper marriage is held.

In the time of reception of the bride, the two 'Bwirathi' used to remain at the forefront and lead the procession towards the house of the groom from the place where the bride's party rested till formally received along with the villagers. In their hands there remains a Sandri (sieve) upon which a circular space is created by moulding the banana flaps and inside it put a lit Alari gasa (oil light) which is kept covered by bamboo fan (gisib). At the time of greeting the bride, they move the fan to give air to the bride. The participants in the procession use to shout all together "Hinjao gwdanni jwi, Jwi hinjao gwdanni jwi" which means Glory, glory to the new bridew (Brahma, 2009: 48). Another maid, sprays rice from a don (bamboo basket) in her hands towards the participants up to the gate of the groom's house.

The bride is made to stand on a wooden plate called 'Gambari Kamplai'(Mwshahary, 2010: 69-70) at the main gate of the groom's house and younger sister of the groom sprinkle holy water and wash her feet with holy water. If the groom has no sister than relative sister performs the duty. It is believed that coming from long distance she must have to purify with holy water. While washing the feet the girls demanded some money from the bride for touching and washing her feet and help to enter into the groom's house. When the reception is over, the bride's party is put into the Noma No (main house) and made it to sit leisurely till the arrival of the moment for marriage ceremony. Till that time, the bride's party is served with Dwi (water), Saha-Muri (tea with fried rice) and Goi-Patwi (betel with leaf) (Mwshahary, 2010-69-70). The audience take chance to play joke with the two Bwirathies with the following words:

\author{
"Wi bwirathi loliya \\ Nwngni babangsin \\ Goi khaonaikao \\ Jwnglai jaliya, jaliya” (Basumatary, 2009: 79).
}

English translation: "Oh! Dear Bwirathi, we are not going to eat betel as you have lazily cut while cutting the items."

The Bwirathis sing the following song and dance:

\author{
"Goi-dedere patwi sinari \\ Daobo ki sunwi \\ Motham lanjai badi thangkhu; \\ Khao regang khaodw
}




\author{
Ja regang jadw \\ Sona muki kuga Mwina mukin rao \\ Apathni bwrai-bento \\ Sikla jwhwlao"( Brahma, 2009: 41).
}

English translation: "Round small betel, beautiful nut leaves, lime like heron stool, tobacco like mongoose tail, cut on betel gladly, eats with gay, golden mouth yours, speech like maina, elders in the audience, bravo the heroine!"

When the marriage party arrives, the two Bwiratis leads the procession towards the place, where the proceeding shall be conducted. The 'Bathau Haba' (marriage before Bathau) is the traditional system of the Bodo marriage. In this case, from Noma No (main house), the bride and bridegroom party is brought in the procession in front of the Bathau which is located at the North-East corner of the courtyard. An 'Oja' (priest) performs the proceeding of the marriage. One cock and one hen are sacrificed at the altar of the Bathau. The new couple will kneel down before the altar till the marriage proceeding is over. The Oja binds ends of the cloth being worn by couples as nuptial knot and newlywed couple respects the Oja by kneeling down and touching his feet. Then the Oja recite the following:

\author{
"Aham de, Sanni giri sanja \\ Mwdaini giri Bwrai Bathau Moharaja, \\ Dainigiria dai kalamwbla \\ Nimaha giri nwng. \\ Jwngni mwjang-gajri Nidan-apwt, rog biadniprai \\ Pwtangraya nwngnw. \\ Nwi dinwi bipa guru \\ Amwkaya amwkikao bihamjw laibai, \\ Dinwi bininw nwngnw akai-laru \\ Angkam Engkri hwnai jabai, \\ Najaodw nwng Apa Guru. \\ Bihamjwni munga amwki \\ Samprwmbw suk by suk laki \\ Apa nwngtanga mini kusi najaonanwi \\ Bwr-asirbad hwdw. \\ Jwnghalai swr dongbaoyw \\ Nailo-jalo nwng bipa Gurulo \\ Gole-gole kulumw jwng”"( Brahma, 2009: 49-50)
}

After the marriage proceeding is over, the new bride and groom serve Wngkham (rice) to the people assembled. First of all, the bride has to serve food to her groom alone, with the Ondla (rice curry) prepared specially without turmeric and salt. Through this social institution, the Bodos tie two matured boy and girl into a Nuptial Knot and help to lead a conjugal life with a purpose of being reproduction.

\title{
Marriage of Brahma Dharma:
}

The Bodos who follows Brahma Dharma performs the wedding ceremony in a different way. Of course, they have not given up all the traditional custom of the pre-marriage ceremonies. In fact, many of the traditional customs associated with the pre-marriage ceremonies are followed by them. The difference is emphasized only on religious distinction. Bathou followers perform in front of the 'Altar Bathou' however; Brahma followers perform in front of 'Puja Mandap'(Devi, 2007: 102)They use tea and puffed rice (muri) instead of rice-beer (jau gisi) and pork (oma bedor) during the ceremony.

The two Bwirathi lead the bride and bridegroom to come out from the Noma No accompanying along with a girl for bride who is called lwgw (bride's friend) and a boy called methor (assistant groom) for groom to the altar of the Mandap raising slogans by the villagers as hinjao gwdanni jwi, (victory to the bride) howa gwdanni jwi (Victory to the bridegroom) sound played by band-party. The new couples are made to take seven rounds around the mandap anti-clockwise. After that the Purohit (Priest) call new couple to sit on the mat covered clean by sima (cover cloth) to the western side, facing towards the East of the mandap. The groom sits on the right side of the bride, methor (assistant groom) sits on the right of the groom and lwgw (bride's friend) sits bride's left side, remaining girls and women use to sit around and nearby the bride. 
The Purohit stars the proceeding of the marriage. He calls bride's father to pray to God standing before the blazing fire of Yajnahuthi uttering the following mantra:

"Om aiahi barde devi trayakshare brahma badini gayatri sandasang matoh brahmajani nomohastyute" (Mahinimahan, Chattapadhay; Sarnitya Kriya, 1382: 89).

English translation: Oh, mother of the Earth, you will come and say at my heart, you are the Brahma, you are the mother of the earth, you have created this Universe; I salute you.

The bride's father chants above mantra three times following the Purohit and bows the blazing fire of the Yajna every time while the mantra ends. The father of the bride offers mixed corns (rice, pulse, flowers etc.) to the fire chanting the mantra as:

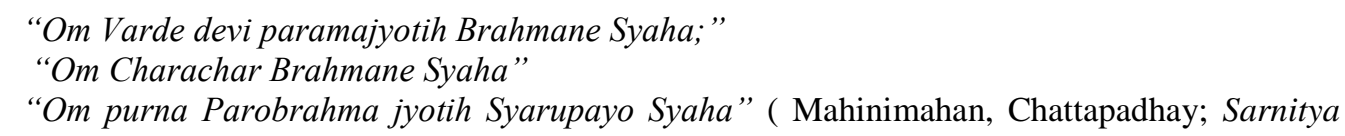
Kriya, 1382: 89)

English translation:

"I offer this corn to you,

Who is the light of lights and

Who blesses us;

To you, who is present

Everywhere with both movable

And immovable things,

Who is the full Brahma

And who is visible

As the light."

While offering is over, father of the bride prays to the God for blessings to bride and bridegroom and declares attending people that he had handed over his daughter to the bridegroom for whole life. The Purohit binds the nuptial knot of the bride and bridegroom. Then the bride and bridegroom chant 'Gayatrimantra' jointly and offer the 'Prasad' (mixed corns) to the 'Mandap' praying to the God. According to Jyotish Chandra Narzary, earlier days, there was no use of 'Sindoor' to bride. But, now days, it is become a indispensible in the marriage system of the Bodos becaouse of Hindunisation (Informant: Shri Jyotish Chandra Narzary; age 59 years, Serfanguri Kumguri, Kokrajhar).

Marriage the Bodo can perhaps hardly be looked upon as a religious character, but it is regarded as more of the nature of a social and festive gathering (Endle, 1911). No doubt, numbers of rites, rituals and ceremonies are associated in the marriage of the Bodo. Without the rituals ceremony a marriage can not be performed as the rites and the rituals are made compulsory in the marriage of the Bodo. We may rightly conclude that the marriage of the Bodo is an institution with religious character.

\section{REFERENCES:}

[1] Dr. Sekhar Brahma, Religion of the Boro And Their Socio-Cultural Transition, DVS Publishers Guwahati, 2006 P-21

[2] Baben Narzee, Boro Kocharini Somaj Arw Harimu, Chirang Publication Board, 2006, P-79

[3] Kameswar Brahma, A Study in Cultural Heritage of the Bodos, Guwahati, Bina Library Guwahati: Assam, 2009, P-65

[4] Dr. K. Brahma, Aspect of Social Customs of the Bodos, Bina Library Guwahati: Assam, 2008, P-25

[5] Premlata Devi, Social and Religious Institutions of Bodos, 2007, P-97

[6] Informant : Bena Brahma, Age 60 Years, Vill- Santinagar, Dotma

[7] Dharani Kanta Narzary, Age 62, Vill- Laokriguri, Kokrajhar

[8] Binoy Kumar Brahma, Boroni Subung Harimu, N.L. Publications Kokrajhar, BTC, 2009, P-48

[9] Birendra Giri Basumatary, Boro Harimuni Mohor Mushri, N.L. Publications Panbazar: Guwahati, 2009, P-79

[10] Informant: Shri Darani Kanta Narzary; Age 65 Years, Serfanguri Laokriguri, Kokrajhar.

[11] Mahinimahan, Chattapadhay; Sarnitya Kriya, Calcutta, P-89

[12] Informant: Shri Jyotish Chandra Narzary; Age 59 Years, Serfanguri Laokriguri, Kokrajhar 
